\title{
Clinical Outcomes of Upper Gastrointestinal Bleeding in Egyptian Patients with Decompensated Liver Cirrhosis, Does the Bleeding Source Matter? Mohamed S Mohamed, Mohamed G Hamed, Amr S Hanafy, Mohamed AA Bassiony \\ Internal Medicine Department, Faculty of Medicine, Zagazig University \\ Corresponding author: Mohamed Bassiony, Telephone: 01006680215, E-mail: dr_mbh13303@yahoo.com
}

\begin{abstract}
Background: Upper gastrointestinal bleeding (UGIB) is a prevalent emergency and mortality cause in cirrhotic patients. It prolongs the hospital length of stay (LOS) and increases hospital readmission.

Objectives: We investigated the clinical outcomes of acute variceal bleeding (AVB) and non-variceal bleeding (NVB) in patients with decompensated cirrhosis and the possible risk factors for prolonged hospital LOS.

Patients and Methods: All patients with decompensated liver cirrhosis and UGIB (AVB \& NVB) hospitalized from August 2018 to March 2019 were enrolled in this study. We assessed mortality rate, the hospital LOS and hospital readmission rate along with the probable risk factors associated with prolonged hospital LOS.

Results: Our study included 582 patients with decompensated liver cirrhosis, 367 patients had AVB and 215 patients had NVB. There was no significant difference in mortality rate between both groups $(11.4 \%$ vs. $9.3 \%, \mathrm{P}=0.43)$. The hospital LOS in AVB patients was longer than that in NVB group $(5.8 \pm 2.2$ vs. $4.3 \pm 1.8, \mathrm{p}=0.001)$. Rate of hospital re-admission within 30 days was significantly higher in the AVB group (27\%) compared to NVB group (18\%). Inhospital re-bleeding and the need for repeated endoscopy were also higher in AVB patients (20\%) than in NVB patients (12\%). Risk factors for prolonged hospital LOS were development of hepatic encephalopathy, spontaneous bacterial peritonitis (SBP), in-hospital re-bleeding, Child C score and higher Model for end-stage liver disease (MELD) score.

Conclusion: Patients with decompensated cirrhosis and AVB have longer hospital LOS and re-hospitalization rate than those with NVB with no significant difference in mortality rate between both groups.

Keywords: Decompensated cirrhosis, Variceal bleeding, Non-variceal bleeding, Peptic ulcer, Length of hospital stay, In-hospital re-bleeding.
\end{abstract}

\section{INTRODUCTION}

Liver cirrhosis and its complications are major health burdens in Egypt and worldwide.

Acute UGIB is the most common medical emergency in cirrhotic patients with significant morbidity and mortality. AVB, from esophageal or gastric varices, is the most prevalent type of UGIB in liver cirrhosis patients accounting for up to $70 \%$ of all cases, while NVB is responsible for the remaining percentage of UGIB. Despite the sophisticated advancements in endoscopic procedures, hemostatic therapies and medical management in the previous few years, high mortality rate from UGIB in patients with decompensated liver cirrhosis still represents a significant health problem ${ }^{(\mathbf{1}, \mathbf{2}) \text {. }}$

Following AVB, patients with decompensated cirrhosis may develop spontaneous bacterial peritonitis, aspiration pneumonia and respiratory failure, renal failure due to hypovolemia or hepatorenal syndrome, worsening of liver function, and hepatic encephalopathy, with a 6-week mortality rate up to $20 \%{ }^{(3,4)}$.

NVB refers to any other causes of UGIB other than AVB. Peptic ulcer disease (PUD) represents the most common cause. It also includes bleeding from other sources such as esophagitis, gastritis, portalhypertensive gastropathy and gastric vascular ectasia and Mallory-Weiss tear ${ }^{(5,6)}$. Bleeding peptic ulcer has a significantly higher mortality rate in patients with liver cirrhosis than in those without liver disease, most probably due to altered coagulation in hepatic patients with a 6-week mortality up to $13 \%{ }^{(7)}$.

UGIB in decompensated cirrhosis increases the hospital LOS, 30-days hospital readmission and augments the spending on healthcare programs ${ }^{(\mathbf{8}) \text {. }}$

\section{PATIENTS AND METHODS}

This was a prospective study, included 582 patients with decompensated cirrhosis, who were admitted with UGIB to Internal Medicine Department at Zagazig University Hospitals from August 2018 to March 2019.

Inclusion criteria included age $>18$ years old, both sexes, clinical, laboratory and ultrasound data supporting decompensated liver cirrhosis (Child score B \& C), clinical evidence of UGIB including hematemesis and/or melena and upper GI endoscopy done within 24 hours of onset of bleeding.

Exclusion criteria: Patients were excluded from the study if they had one or more of the following criteria: Child score A, advanced hepatic encephalopathy on admission, death or discharge before endoscopy, if patients refused to be enrolled in the study and patients 
with incomplete medical records.

All patients underwent thorough history taking and clinical examination to detect features of vascular or cellular hepatic decompensation as jaundice, bleeding tendency, feter hepaticus, palmar erythema, spider nevi, hepatosplenomegaly, ascites and lower limb oedema.

Investigations included complete blood count (CBC), liver \& kidney function tests, coagulation profile, fasting blood glucose level, in addition to abdominal ultrasound with Doppler. Emergency upper GI endoscopy was done for all patients included in the study after stabilization.

\section{According to endoscopic findings, the patients were classified into 2 groups:}

AVB group: included 367 patients with esophageal and/or gastric varices

NVB group: included 215 patients with any source of bleeding other than varices e.g: PUD, esophagitis, gastric vascular ectasia, Dieulafoy lesion etc.

All patients were assessed by scores reflecting liver function status including Child, MELD, Glasgow-Blatchford, AIMS65 and Rockall scores ${ }^{(9) .}$

Clinical outcomes were compared between AVB and NVB patients, including hospital LOS, need for ICU admission, packed red blood cells (RBCs) transfusion rate, in-hospital re-bleeding \&/or repeated endoscopy during admission (within 73 hours), 30-days rehospitalization rate and in-hospital mortality.

\section{Ethical approval:}

All patients gave written informed consents to participate in the study. The study protocol conformed to the ethical guidelines of the 1975 Declaration of Helsinki and was approved by the Ethical Committee of Zagazig University Hospitals and Zagazig University Institutional Review Board (IRB).

\section{Statistical analysis}

It was done using statistical package for the social sciences (SPSS) version 22. Quantitative variables were presented as range and mean \pm standard deviation (SD) while qualitative variables were presented as percentage. Chi-square test and Fishers' Exact test were used for qualitative variables. Student t-test and regression analysis for quantitative variables. Statistical significance was considered with $\mathrm{p} \leq 0.05$.

\section{RESULTS}

Table (1) showed that patients in NVB group were older in age with history of more use of nonsteroidal anti-inflammatory drugs (NSAIDs) \& more use of proton pump inhibitors (PPI) compared to AVB group. There were no statistically significant differences between both groups regarding sex, smoking, comorbidities as diabetes mellitus (DM), use of beta-blockers or history of previous bleeding episodes.

Table (2) showed that AVB patients had less platelet count, more prolonged INR, higher MELD score \& higher Glasgow-Blatchford score in comparison with NVB patients. Both groups of patients had no statistically significant differences on admission regarding vital signs, hemoglobin concentration, serum albumin, bilirubin \& creatinine levels. In addition, there were no significant differences between both groups regarding Child, AIMS65 \& Rockall scores.

Table (3) showed that AVB patients had more prolonged hospital LOS, more frequent in-hospital rebleeding episodes, repeated endoscopy \& more 30-day hospital re-admission by UGIB compared to NVB patients. However, there were no statistically significant differences between both groups regarding mortality rates, ICU admission and frequency of packed RBCs transfusion.

The most important risk factors associated with prolonged hospital LOS in our patients with decompensated cirrhosis and UGIB (both AVB \& NVB) were development of hepatic encephalopathy, SBP, in-hospital re-bleeding, MELD score $\geq 12$ and patients with Child score $\mathrm{C}$ as shown in table (4).

Table1: Demographic data of the study groups

\begin{tabular}{|c|c|c|c|}
\hline & $\begin{array}{l}\text { AVB Group } \\
(\mathbf{N}=367)\end{array}$ & $\begin{array}{l}\text { NVB Group } \\
(\mathbf{N}=\mathbf{2 1 5})\end{array}$ & p. Value \\
\hline Age (years) & $47.8 \pm 11.5$ & $50.3 \pm 9.1$ & 0.001 \\
\hline Males (\%) & $272(74.1 \%)$ & $156(72.6 \%)$ & 0.69 \\
\hline Smoking & $108(29.4 \%)$ & $79(36.7 \%)$ & 0.07 \\
\hline Diabetes Mellitus & $145(39.5 \%)$ & $82(38.1 \%)$ & 0.74 \\
\hline NSAIDs use & $67(18.3 \%)$ & $59(27.4 \%)$ & 0.01 \\
\hline \begin{tabular}{|l|} 
PPI use \\
\end{tabular} & $111(30.2 \%)$ & $91(42.3 \%)$ & 0.003 \\
\hline Beta-Blockers treatment & $258(70.3 \%)$ & $143(66.5 \%)$ & 0.34 \\
\hline $\begin{array}{l}\text { Previous bleeding } \\
\text { episodes }\end{array}$ & $158(43.1 \%)$ & $87(40.5 \%)$ & 0.54 \\
\hline
\end{tabular}


Table 2: Clinical and laboratory data of both groups on admission

\begin{tabular}{|l|l|l|l|}
\hline & $\begin{array}{l}\text { AVB Group } \\
\text { (N = 367) }\end{array}$ & $\begin{array}{l}\text { NVB Group } \\
\text { (N= 215) }\end{array}$ & p. Value \\
\hline Heart Rate & $105 \pm 17$ & $107 \pm 19$ & 0.19 \\
\hline Systolic BP (mmHg) & $102 \pm 13$ & $104 \pm 15$ & 0.09 \\
\hline Hemoglobin level (gm \%) & $8.6 \pm 1.2$ & $8.5 \pm 1.8$ & 0.42 \\
\hline Platelet count & $101 \pm 22$ & $113 \pm 16$ & $\mathbf{0 . 0 0 1}$ \\
\hline INR & $1.8 \pm 0.5$ & $1.6 \pm 0.8$ & $\mathbf{0 . 0 0 1}$ \\
\hline Albumin (g/dl) & $2.9 \pm 0.6$ & $3 \pm 0.7$ & 0.07 \\
\hline Total bilirubin (mg/dL) & $1.9 \pm 0.09$ & $1.8 \pm 0.07$ & 0.16 \\
\hline Creatinine (mmol/day) & $1.3 \pm 0.04$ & $1.2 \pm 0.04$ & 1 \\
\hline MELD & $17 \pm 3.2$ & $16 \pm 3.5$ & $\mathbf{0 . 0 0 1}$ \\
\hline $\begin{array}{l}\text { Child score } \\
\text { B } \\
\text { C }\end{array}$ & $152(41.4 \%)$ & $98(45.6 \%)$ & 0.32 \\
\hline $\begin{array}{l}\text { Glasgow-Blatchford } \\
\text { Score }\end{array}$ & $15 \pm 1.4$ & $117(54.4 \%)$ & \\
\hline AIMS65 Score & $2.6 \pm 0.6$ & $13 \pm 1.7$ & $\mathbf{0 . 0 0 1}$ \\
\hline Rockall Score & $7 \pm 1.1$ & $2.5 \pm 0.7$ & 0.07 \\
\hline
\end{tabular}

Table 3: Clinical outcomes in the study groups

\begin{tabular}{|l|l|l|l|}
\hline & $\begin{array}{l}\text { AVB Group } \\
(\mathbf{N}=367)\end{array}$ & $\begin{array}{l}\text { NVB Group } \\
(\mathbf{N}=\mathbf{2 1 5})\end{array}$ & p. Value \\
\hline ICU admission & $310(84.5 \%)$ & $181(84.2 \%)$ & 0.92 \\
\hline Hospital LOS & $5.8 \pm 2.2$ & $4.3 \pm 1.8$ & $\mathbf{0 . 0 0 1}$ \\
\hline $\begin{array}{l}\text { Packed RBCs } \\
\text { transfusion }\end{array}$ & $231(62.9 \%)$ & $128(59.5 \%)$ & 0.42 \\
\hline $\begin{array}{l}\text { In-hospital re-bleeding } \\
\begin{array}{l}\text { 30-day Re- } \\
\text { hospitalization }\end{array}\end{array}$ & $74(20.2 \%)$ & $26(12.1 \%)$ & $\mathbf{0 . 0 1}$ \\
\hline \begin{tabular}{l} 
Mortality rate \\
\hline
\end{tabular} & $42(11.4 \%)$ & $39(18.1 \%)$ & $\mathbf{0 . 0 2}$ \\
\hline
\end{tabular}


Table 4: Risk factors for prolonged hospital LOS in the study groups

\begin{tabular}{|c|c|c|c|c|}
\hline & $\begin{array}{l}\text { LOS in AVB } \\
\text { Group } \\
(\mathbf{N}=367)\end{array}$ & p. Value & $\begin{array}{l}\text { LOS in NVB Group } \\
(\mathrm{N}=215)\end{array}$ & p. Value \\
\hline $\begin{array}{l}\text { Age } \\
<50 \text { years } \\
\geq 50 \text { years }\end{array}$ & $\begin{array}{l}5.7 \pm 1.7 \\
5.9 \pm 1.6\end{array}$ & 0.25 & $\begin{array}{l}4.3 \pm 1.2 \\
4.5 \pm 1.1\end{array}$ & 0.27 \\
\hline $\begin{array}{l}\text { Male } \\
\text { Female }\end{array}$ & $\begin{array}{l}5.4 \pm 1.3 \\
5.2 \pm 0.9\end{array}$ & 0.24 & $\begin{array}{l}4.2 \pm 0.9 \\
4.3 \pm 0.7\end{array}$ & 0.45 \\
\hline $\begin{array}{l}\text { DM } \\
\text { Yes } \\
\text { No }\end{array}$ & $\begin{array}{l}5.8 \pm 1.3 \\
5.6 \pm 1.1\end{array}$ & 0.25 & $\begin{array}{l}4.6 \pm 1.1 \\
4.5 \pm 0.8\end{array}$ & 0.5 \\
\hline $\begin{array}{l}\text { NSAIDs use } \\
\text { Yes } \\
\text { No }\end{array}$ & $\begin{array}{l}5.6 \pm 1.5 \\
5.9 \pm 1.4\end{array}$ & 0.65 & $\begin{array}{l}4.4 \pm 1.2 \\
4.2 \pm 0.9\end{array}$ & 0.19 \\
\hline $\begin{array}{l}\text { Beta-Blockers use } \\
\text { Yes } \\
\text { No }\end{array}$ & $\begin{array}{l}5.4 \pm 1.9 \\
5.9 \pm 2.1\end{array}$ & 0.07 & $\begin{array}{l}3.9 \pm 0.9 \\
4.1 \pm 1.1\end{array}$ & 0.15 \\
\hline $\begin{array}{l}\text { previous bleeding episode } \\
\text { Yes } \\
\text { No }\end{array}$ & $\begin{array}{l}5.8 \pm 1.5 \\
5.4 \pm 1.6 \\
\end{array}$ & 0.07 & $\begin{array}{l}4.6 \pm 1.2 \\
4.5 \pm 1.4 \\
\end{array}$ & 0.58 \\
\hline $\begin{array}{l}\text { Encephalopathy } \\
\text { Yes } \\
\text { No } \\
\end{array}$ & $\begin{array}{l}6.7 \pm 1.8 \\
4.8 \pm 1.7 \\
\end{array}$ & 0.001 & $\begin{array}{l}6.2 \pm 1.6 \\
4.6 \pm 1.8 \\
\end{array}$ & 0.001 \\
\hline $\begin{array}{l}\text { SBP } \\
\text { Yes } \\
\text { No }\end{array}$ & $\begin{array}{l}6.2 \pm 1.6 \\
4.9 \pm 1.9\end{array}$ & 0.002 & $\begin{array}{l}5.1 \pm 1.8 \\
3.5 \pm 1.3\end{array}$ & 0.001 \\
\hline $\begin{array}{l}\text { In-hospital re-bleeding } \\
\text { Yes } \\
\text { NO }\end{array}$ & $\begin{array}{l}6.8 \pm 2.1 \\
4.1 \pm 1.7 \\
\end{array}$ & 0.001 & $\begin{array}{l}6.2 \pm 1.9 \\
3.9 \pm 0.9 \\
\end{array}$ & 0.001 \\
\hline $\begin{array}{l}\text { MELD score } \\
<12 \\
\geq 12\end{array}$ & $\begin{array}{l}4.9 \pm 1.5 \\
5.9 \pm 1.9\end{array}$ & 0.001 & $\begin{array}{l}3.8 \pm 0.8 \\
4.5 \pm 1.7\end{array}$ & 0.001 \\
\hline $\begin{array}{l}\text { Child score } \\
\text { B }\end{array}$ & $5.7 \pm 1.4$ & 0.001 & $4.9 \pm 1.9$ & 0.001 \\
\hline C & $6.9 \pm 1.9$ & & $5.9 \pm 2.1$ & \\
\hline
\end{tabular}

\section{DISCUSSION}

Liver cirrhosis and its complications, most commonly secondary to chronic hepatitis $\mathrm{C}$ infection, are major public health problems in Egypt \& worldwide with a great burden on health system \& the national economy. Acute UGIB is the most common complication of liver cirrhosis \& is associated with poor clinical outcomes, high recurrence rates and significant mortality in comparison to the non-cirrhotic patients ${ }^{(10)}$.

Despite the major advances in endoscopic procedures \& endoscopic therapeutic approaches and the great improvements in medical management, UGIB in patients with decompensated cirrhosis still has significant mortality rates and prolonged hospital LOS with increased economic burdens ${ }^{(11)}$.
In our study, we found that NVB patients were significantly older in age with more frequent use of NSAIDs \& PPI than AVB patients. This goes in agreement with findings reported by Zheng $\boldsymbol{e t}$ al. ${ }^{(12)}$ and Alharbi et al. ${ }^{(13)}$ where they reported more frequent previous bleeding episodes in AVB compared to NVB patients. However, in our study both groups had similar frequency of previous bleeding episodes.

Our study showed that AVB patients had lower platelet count, more prolonged INR, higher MELD \& Glasgow-Blatchford scores compared to NVB patients with no statistically significant differences in hemoglobin, albumin, bilirubin \& creatinine levels. Tandon et al. ${ }^{(14)}$ reported similar clinical \& laboratory parameters on admission between AVB \& NVB cirrhotic patients including platelet count, INR with 
the exception of serum creatinine which was higher in NVB patients.

Our results revealed that AVB patients had more prolonged hospital LOS, more in-hospital re-bleeding $\&$ repeated endoscopy rate and more rates of 30-day hospital re-admission due to UGIB compared to NVB patients. However, the mortality rates, ICU admission $\&$ frequency of packed RBCs transfusion were similar between both groups. Similar results were reported by Tandon et al. ${ }^{(14)}$ and Farag et al. ${ }^{(15)}$ who reported a lower mortality rate in NVB patients (4.5\%) compared to our results $(9.3 \%)$ \& Tandon results most probably due to the smaller cohort of patients in Farag et al study.

Our results showed that the risk factors that prolong hospital LOS in this cohort of patients included development of hepatic encephalopathy, SBP, in-hospital re-bleeding and need for reendoscopy, higher MELD score \& Child C patients. Similar results were reported by Fouad et al. (10), Zheng et al. ${ }^{(12)}$, Elwakil et al. ${ }^{(16)}$ and Khairy et al. (16).

\section{CONCLUSION}

This study showed that patients with decompensated cirrhosis and AVB experienced longer hospital LOS, more in-hospital re-bleeding and more 30-day re-hospitalization than those with NVB. The most significant risk factors for a longer hospital LOS were occurrence of hepatic encephalopathy, SBP, hospital re-bleeding \& advanced liver disease (MELD score $\geq 12$ \& Child score $C$ patients).

Declaration of interest: The authors declare that they have no competing interests.

\section{REFERENCE}

1. Sostres C, Lanas A (2011): Epidemiology and Demographics of Upper Gastrointestinal Bleeding: Prevalence, Incidence, and Mortality. Gastrointest Endosc Clin N Am., 21: 567-81.

2. Afessa B, Kubilis P (2000): Upper gastrointestinal bleeding in patients with hepatic cirrhosis: clinical course and mortality prediction. Am J Gastroenterol., 95: 484-89.

3. Crooks C, Card T, West J (2011): Reductions in 28day mortality following hospital admission for upper gastrointestinal hemorrhage. Gastroenterology, 141: 62-70.

4. Lau J, Barkun A, Fan D et al. (2013): Challenges in the management of acute peptic ulcer bleeding. Lancet, 381: 2033-43.

5. Holland-Bill L, Christiansen C, Gammelager H et al.
(2015): Chronic liver disease and 90-day mortality in 21,359 patients following peptic ulcer bleeding: a Nationwide Cohort Study. Aliment Pharmacol Ther., 41: 564-72.

6. Leontiadis G, Molloy-Bland M, Moayyedi P et al. (2013): Effect of comorbidity on mortality in patients with peptic ulcer bleeding: systematic review and metaanalysis. Am J Gastroenterol., 108: 331-45.

7. Olmo J, Peña A, Serra M et al. (2000): Predictors of morbidity and mortality after the first episode of upper gastrointestinal bleeding in liver cirrhosis. J Hepatol., 32: 19-24.

8. Seraj S, Campbell J, Argyropoulos S et al. (2017): Hospital readmissions in decompensated cirrhotics: Factors pointing toward a prevention strategy. World $\mathrm{J}$ Gastroenterol., 23: 6868-76.

9. Kuba M, Arzate A, Avila F et al. (2016): Validation of prognostic scores for clinical outcomes in cirrhotic patients with acute variceal bleeding. Annals of Hepatology., 15 (6): 895-901.

10. Fouad T, Abdelsameea E, Abdel- Razek W et al. (2019): Upper gastrointestinal bleeding in Egyptian patients with cirrhosis: Post- therapeutic outcome and prognostic indicators. J Gastroenterol Hepatol., 34 (9): 1604-10.

11. Ardevol A, Ibañez-Sanz G, Profitos J et al. (2018): Survival of patients with cirrhosis and acute peptic ulcer bleeding compared with variceal bleeding using current first-line therapies. Hepatology, 67: 1458-71.

12. Zheng L, Sun X, Han J et al. (2019): Characteristics of peptic ulcer bleeding in cirrhosis with esophageal and gastric varices. Doi:10.21203/rs.2.12787/v1

13. Alharbi A, Almadi M, Barkun A et al. (2012): Predictors of a variceal source among patients presenting with upper gastrointestinal bleeding. Can $\mathbf{J}$ Gastroenterol., 26 (4): 187-192.

14. Tandon P, Bishay K, Fisher $S$ et al. (2018): Comparison of clinical outcomes between variceal and non-variceal gastrointestinal bleeding in patients with cirrhosis. J Gastroenterol Hepatol., 33: 1773-9.

15. Farag A, Jouda A, Moustafa E et al. (2019): Nonvariceal Causes and Outcome of Acute Upper Gastrointestinal bleeding among Cirrhotic Patients in Tropical Medicine Intensive Care Unit. Afro-Egyptian journal of Infectious and endemic diseases, 9 (4): 270-279.

16. Elwakil M, Reda M, Abdelhakam S et al. (2011): Causes and outcome of upper gastrointestinal bleeding in Emergency Endoscopy Unit of Ain Shams University Hospital of the Egyptian Society of Parasitology. https://www.researchgate.net/publication/51700425

17. Khairy M, Ghaliony M, Mohammed H (2014): Outcomes and predictors of in-hospital mortality among cirrhotic patients with non-variceal upper gastrointestinal bleeding in upper Egypt. Turk J Gastroenterol., 25: 707-713. 